\title{
O planejamento regional no Centro-Oeste brasileiro: ações da SUDECO e a região geoeconônima de Brasília ${ }^{1}$
}

\author{
Patricia Freitag, \\ Rodrigo Santos de Faria*
}

\begin{abstract}
Resumo Esse artigo investiga a política de desenvolvimento regional da SUDECO. Entender como as diferenciações regionais delineadas pelo sistema capitalista nacional foram abordadas pelo Estado e como essas distinções determinaram o modo de intervenção governamental sobre o território nacional. Com base nessa compreensão, avançaremos para uma leitura das características do Centro-Oeste e da forma como essa região foi inserida no modelo de desenvolvimento traçado a partir de 1964 e o papel da SUDECO nesse processo de reestruturação territorial regional. Por fim, buscaremos investigar os principais fatores motivadores da configuração espacial de Brasília enquanto aglomerado urbano nas duas primeiras décadas que sucederam a sua construção e suas vinculações com as medidas traçadas pelo Estado brasileiro para o Centro-Oeste.
\end{abstract}

Palavras-chave: planejamento regional, metropolização, Brasília.

\section{El planeamiento regional en el Centro Oeste brasileño: las acciones de la SUDECO y la región geoeconómica de Brasília}

Resumen Este artículo investiga la política de desarrollo regional de SUDECO. Entender cómo las diferenciaciones regionales delineadas por el sistema capitalista nacional fueron abordadas por el Estado y cómo estas distinciones determinaron el modo de intervención del gobierno en el territorio nacional. Luego, procederemos a una lectura de las características del Medio Oeste y de la forma en que esta región se insertó en el modelo de desarrollo trazado desde 1964 y el papel de SUDECO en este proceso de reestructuración territorial regional. Finalmente, buscaremos investigar los principales factores motivadores para la configuración espacial de Brasilia como aglomeración urbana en las dos primeras décadas que siguieron a su construcción y sus vínculos con las medidas delineadas por el Estado brasileño para el Medio Oeste.

Palabras clave: planificación metropolitana, metropolización, Brasilia.
Regional planning in Central West of Brazil: SUDECO actions and the geoeconomic region of Brasília

\begin{abstract}
This article investigates the regional development policy outlined by SUDECO. Understand how the regional differentiations outlined by the national capitalist system were approached by the State, and how these distinctions determined the mode of government intervention over the national territory. We will proceed to a reading of the characteristics of the Brazilian Midwest and of how this region was inserted in the development model firstly drawn in 1964, as well as will discuss the role of SUDECO in this process of regional territorial restructuring. Finally, we will investigate the main motivating factors of the spatial configuration of Brasilia as an urban cluster in the first two decades that followed its construction, and its links with the measures drawn by the Brazilian state to the Midwest.
\end{abstract}

Key words: regional planning, metropolization, Brasília. 


\section{A emergência da questão regional no Brasil}

A lógica espacial do capitalismo imprime-se no território de forma seletiva, atribuindo diferenciações entre os lugares. Como resultado, percebem-se distinções nas bases locais e regionais do processo de valorização do capital, culminando em peculiaridades espaciais no que tange às formas de produção e reprodução do capital, ou seja, em tipos específicos de estruturas geográficas.

Tendo como referência as reflexões de Marx, Harvey observa que o crescimento harmonioso ou equilibrado é inteiramente acidental, devido à natureza espontânea e caótica da produção de mercadorias sob o capitalismo competitivo (HARVEY, 2006, p. 44). Por isso, configuram-se territórios de desolação social e econômica, de onde são liberadas verdadeiras levas de migrantes rumo às regiões de maior crescimento e oportunidades de melhoria de vida. Esse quadro retrata a lógica de uma economia de exploração permeada por contradições, crises e instabilidades internas, culminando na conformação de uma certa "lei da dialética", da interpenetração dos contrários. Segundo Baggio,

Trata-se de uma característica imanente à realidade, contradição que opera como elemento motor de sua própria transformação. Essa lei encerra uma dimensão espacial que se consubstancia no processo de regionalização, ou seja, de diferenciação de áreas. (BAGGIO, 2008, p. 38)

Nesse sentido, as áreas que se sobressaltam em diferenças, embora apresentem padrões distintos de acumulação do capital, compõem estruturas que se organizam progressivamente integradas por redes, na medida em que são criadas derivações e complementariedades produtivas, de forma que não há como considerar a região como entidade autônoma. A respeito dessa combinação do desenvolvimento desigual, Correa (CORREA, 1995) chama atenção para que esta seja compreendida não apenas como

1 Parte das pesquisas realizadas para este estudo integram as atividades financiadas pela Bolsa CNPq/PQ-2.

* Patricia Freitag é Arquiteta e Urbanista, Professora da Universidade Estadual de Goiás, cargo de Arquiteta-Urbanista do Instituto Federal Goiano, ORCID <https:// orcid.org/0000-0002-36724604>. Rodrigo Santos de Faria é Professor do Departamento de Teoria e História da Arquitetura e Urbanismo da Faculdade de Arquitetura e Urbanismo da Universidade de Brasília (DTHFAUFAU-UNB), ORCID <https://orcid. org/0000-0001-5355-8532>. a coexistência em um mesmo território de diferentes modos de vida, mas igualmente como a conectividade espacial entre os territórios.

Complementarmente, Carleial mostra que os elementos de diferenciação regionais são evidenciados através dos modos específicos de como cada área é inserida na matriz produtiva nacional, com respectivas diferenças em nível de organização da produção e das relações de trabalho, refletindo o movimento de acumulação de capital que se faz desigual. Com base nesse argumento, a autora, ao fazer referências ao Brasil, afirma que é importante considerar que no caso brasileiro isto é extremamente verdadeiro, mesmo, et pour cause, que se considere o processo de integração econômica(CARLEIAL, 1993, p.47).

Nesse mesmo sentido, Francisco de Oliveira reconheceu que as políticas de expansão fundamentadas no modelo de acumulação estabelecidas no Centro-Sul condicionaram as tentativas de desenvolvimento de demais regiões do País às suas demandas imediatas, 
como uma forma de destruição das economias regionais. Tratava-se, portanto, de um movimento que destrói para concentrar, enquanto se apropria do excedente das outras regiões para centralizar o capital . (OLIVEIRA, 1977, p. 76)

Segundo Roberto Monte-Mór (MONTE-MÓR, 2008), esse modelo evidenciava suas incongruências através das regiões deprimidas na medida em que estas se constituem em perda no aproveitamento de recursos humanos e naturais no processo de produção, levando a redução dos ganhos potenciais pela fragilidade de consumo. Assim, a disparidade inter-regional configurou-se como um problema, um entrave ao desenvolvimento nacional, e como tal passou a ser alvo específico de ações governamentais.

Desse modo, a partir da década de 1960, o planejamento tanto nacional quanto regional passou a ser orientado por novos formatos de intervenção, abandonando o enfoque do planejamento de uma região isolada, para o planejamento regional em escala nacional, ou seja, que concebe a elaboração dos planos regionais como parte do planejamento de uma nação como um todo. De acordo com Santana a problemática regional surge pari passu com a necessidade de se viabilizar e potencializar um dado padrão de acumulação capitalista no qual a noção de desenvolvimento regional ocupa lugar central (SANTANA, 2009, p. 59).

Esse modelo de produção regionalmente integrado foi primeiramente apropriado pelo Plano Trienal (1963-1965). Em suas medidas, o documento apresentou de forma pioneira a abordagem da problemática regional mediante propostas de redução das disparidades regionais por meio da promoção de estratégias de localização das atividades econômicas em diferentes localidades do território nacional a fim de evitar

2Ver Brasil, Presidência da República. Plano Trienal de Desenvolvimento Econômico e Social (1963-1965), dezembro de 1962. concentração de investimentos².

Posteriormente, o Plano Decenal (1967-1976) trouxe uma contribuição maior para as políticas de desenvolvimento econômico, mediante diretrizes consubstanciadas em uma compreensão de planejamento regional sob a perspectiva de rede de cidades e do planejamento interurbano. Por esse motivo, o referido plano foi considerado por autores como Steinberger e Bruna (2001); Cintra e Haddad (1978) e Schimdt (1983) como o divisor de águas na forma de se pensar as questões regional e urbana brasileiras.

Com efeito, esse padrão de planejamento estendeu-se ao I PND e II PND. No primeiro, as regiões foram fortemente vinculadas às diretrizes voltadas para o planejamento migratório, que tem por base o remanejamento populacional estruturado de acordo com as especificidades de cada região. Assim, foram estabelecidos polos agroindustriais no Sul, industrial-agrícola do Nordeste e agropecuário da Amazônia e Centro-Oeste (BRASIL, 1972, p. 17). Já no II PND esta relação é apresentada da seguinte forma: a) na área industrial, além da construção do Polo Petroquímico da Bahia, será implantado um Polo de Fertilizantes e um Complexo Metal-Mecânico e Eletromecânico; b) na Agropecuária, com ênfase em sua transformação, serão executados o Programa de Desenvolvimento de Áreas Integradas e o Programa de Desenvolvimento da Agroindústria do Nordeste; c) a ocupação produtiva da Amazônia e do Centro-Oeste receberá impulso com o Programa de Polos Agropecuários e Agrominerais da Amazônia (POLAMAZÔNIA), o Complexo Mínero-Metalúrgico da Amazônia Oriental e o Programa de Desenvolvimento de Recursos Florestais, além da execução de programas especiais, como o de desenvolvimento do Pantanal. (BRASIL, 1975, p. 5). 


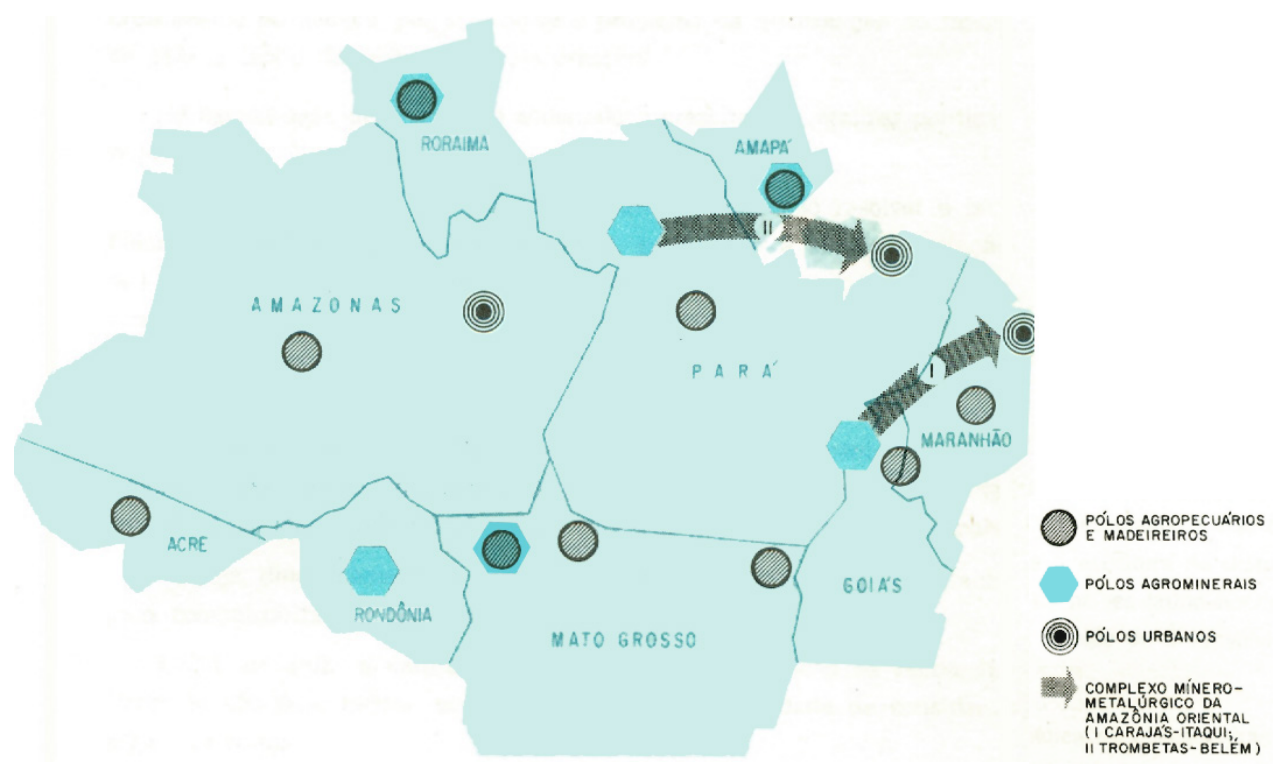

Figura 1: II PND - Plano Nacional de Desenvolvimento. Programa de Pólos Agropecuários e Agromineirais da Amazônia (POLAMAZÔNIA). Fonte: Brasil, 1975, p.67.

3Ver: Vainer (2007)
Ainda que efetivamente existam essas intencionalidades e proposições no âmbito do ॥ PND, faz-se necessário um olhar que explicite as particularidades e possíveis contradições do próprio plano. E especificamente sobre a região Amazônica, é oportuna a observação realizada por Marcílio Sudério, ao afirmar na década 1970 se iniciou mais efetivamente no Amazonas o movimento de concentração mononucleada de inversões federais, inclusive, esse processo teve destaque no texto do II Plano Nacional de Desenvolvimento - Il PND (1975-1979) que, quando trata da "Ocupação Produtiva da Amazônia e do Centro-oeste", elenca quatro campos de atuação do governo, dentre os quais, a "Conclusão do Distrito Industrial da Zona Franca de Manaus e execução de seu Distrito Agropecuário. O texto do Plano de âmbito nacional apresenta o objetivo específico a ser alcançado no Amazonas em meio a outros três a serem fomentados na Amazônia, mas, majoritariamente, fora do território amazonense, com destaque para o Programa de Pólos Agropecuários e Agrominerais da Amazônia (POLAMAZONIA) e o Complexo Mínero-Metalúrgico da Amazônia Oriental é salientável que na parte oriental da região se localizam as propostas espacialmente desconcentradas e em todo território amazonense só há uma indicação do POLAMAZÔNIA (SUDÉRIO, 2020, p. 326-328).

Nesse contexto, tem início de forma mais significativa, o processo de reestruturação do território nacional, em que novos recortes regionais se formatavam a partir da inclusão de novas áreas à rede produtiva ${ }^{3}$, como a reserva mineral de Carajás no estado do Pará e, como é o principal interesse neste estudo, as áreas agriculturáveis quando Centro-Oeste.

Outro fator importante neste processo foi o papel desempenhado pelos macrossetores de infraestrutura e seus consequentes desdobramentos em grandes projetos de investimentos como a CHESFE, FURNAS, Companhia Vale do Rio Doce, Petrobras, entre outras, que segundo Vainer, foram decisivos para produzir uma forma muito particular de integração nacional, ao gerarem nexos entre o núcleo urbano-industrial do Sudeste e o resto do País [...] em muitos casos[...] conformavam, ou pelo menos contribuíam 


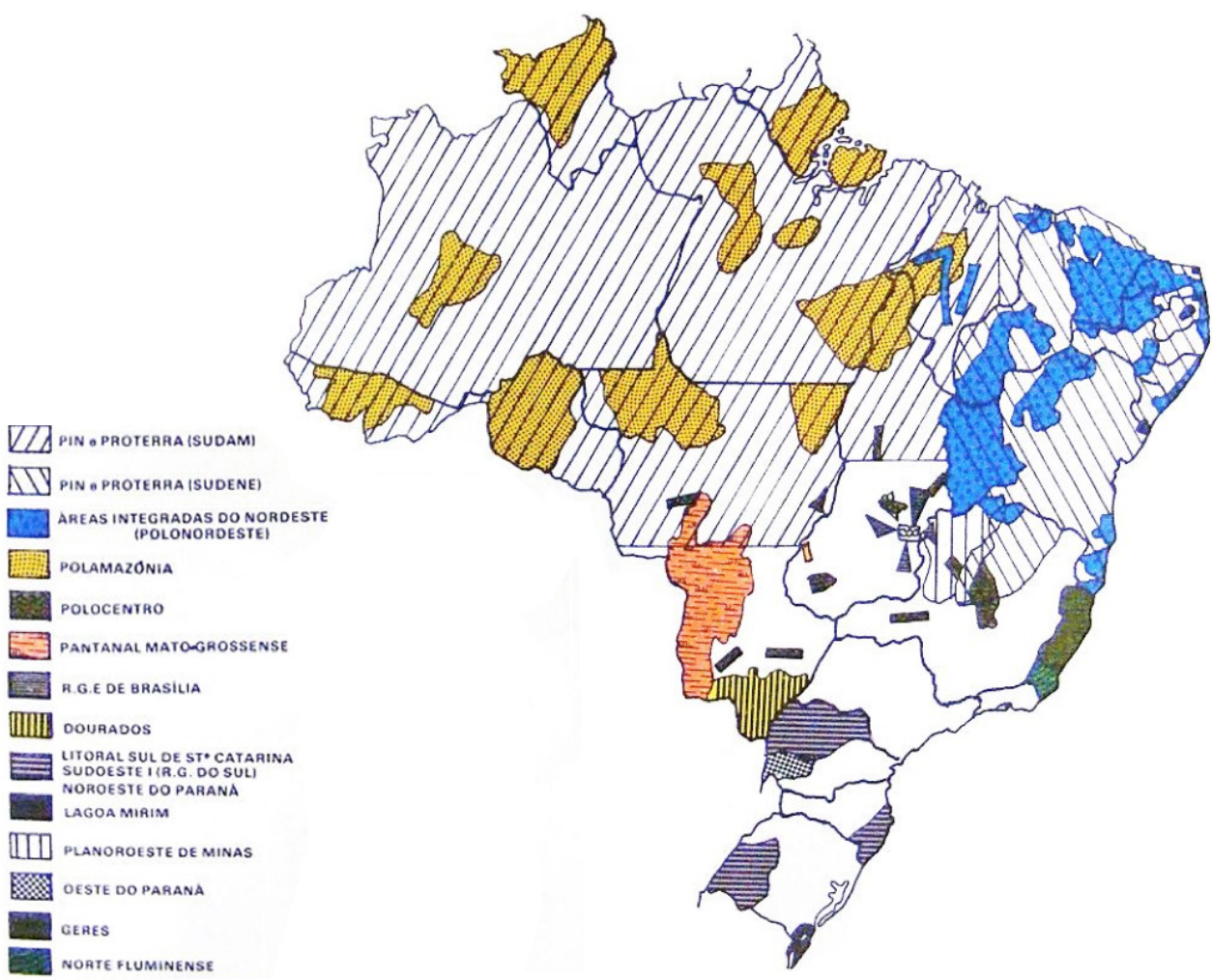

Figura 2: II PND - Programas e Projetos de Desenvolvimento Regional - 1975-1979. Fonte: Anais do I Encontro de Estudos e Debates: O II PND e os Programas de Desenvolvimento da Região do DF e do Centro-Oeste. fortemente para conformar, um espaço nacional integrado - profundamente desigual, mas integrado (VAINER, 2007, p. 11).

Ou seja, de acordo com Vainer (2007), a configuração do território nacional estava associada mais fortemente aos grandes projetos de investimentos que propriamente às agências de planejamento de desenvolvimento regional (Sudene, Sudesul, Sudam, Sudeco). A esse respeito, o autor destaca ainda que não eram os planejadores regionais que desenhavam a região, mas os planejadores e tomadores de decisão em cada um dos macro-setores de infraestrutura, [...] bem como algumas grandes empresas estaduais (VAINER, 2007, p.11).

Na análise de Araújo (ARAUJO, 1993), essas transferências de frações do capital produtivo para regiões menos industrializadas desencadearam duas mudanças importantes: a primeira delas foi intensificação da produção em áreas periféricas não encontrava mais limites regionais como mercado local. O mercado era o nacional e o investimento de seu crescimento era nacional e internacional. A presença do grande capital permitiu as economias do Nordeste, Norte e Centro-Oeste crescerem se se modernizarem, promovendo mudanças rápidas e intensas; a segunda indicava que as dinâmicas econômicas passavam a ser orientadas por elementos cada vez menos locais e cada vez mais nacionais. As regiões deixaram de existir como lócus de acumulação autônoma, embora não tenha se dado uma homogeneização. Com base nesse projeto de desenvolvimento, a ação intervencionista dos militares no âmbito regional passou a se concentrar em Superintendências: Superintendência de Desenvolvimento do Nordeste (SUDENE), Superintendência de Desenvolvimento da Amazônia (SUDAM), 
Superintendência de Desenvolvimento do Sul (SUDESUL) e Superintendência de Desenvolvimento do Centro-Oeste (SUDECO).

Com exceção da SUDENE, que foi criada no governo JK, as demais superintendências foram criadas pelos governos militares. Constituíam-se de natureza autárquica e tinham por finalidade coordenar o desenvolvimento regional através da articulação entre estados e municípios, os ministérios e órgãos federais atuantes na área, tendo em vista a redução das desigualdades regionais por meio da formulação de projetos que potencializassem investimentos produtivos nessas regiões (BRASIL, 1978). Segundo Vainer (VEINER, 2007), esses organismos regionais se constituíam em verdadeiros tentáculos do governo federal centralizador, cuja orientação presumia-se no ordenamento do território sem consonâncias das autoridades estaduais. Como resultado desse modelo, muitas ações governamentais deliberadas nas décadas de 1960 e 1970 tiveram como eixo norteador não as demandas locais, mas sim os interesses da política econômica nacional.

Cabe aqui considerar que, apesar de a integração produtiva ter permitido uma reestruturação do espaço regional do País, não se pode afirmar que houve uma homogeneização ou eliminação dessas espacialidades. Ao contrário, novas especificidades foram criadas, reforçando a presença de partes da economia nacional em parcelas específicas do território, em que cada espaço passou a se integrar diferentemente a ramos e/ou setores da produção nacional. Nesse sentido, podemos afirmar que a integração produtiva trouxe à vida diferentes espaços do território brasileiro ao atribuir, a cada qual, funções específicas conforme as respectivas potencialidades. Esse foi o caso da região Centro-Oeste, que a partir da década de 1960 foi posicionada como uma das regiões promissoras pela sua posição geográfica e características naturais, sociais e econômicas, resultando em consideráveis transformações em sua estrutura demográfica.

\section{A região Centro-Oeste no contexto desenvolvimentista}

A macrorregião Centro-Oeste é formada atualmente pelos estados de Goiás, Mato Grosso, Mato Grosso do Sul e o Distrito Federal. Conforme o censo do IBGE de 2010, sua extensão corresponde a $18,8 \%$ do território nacional e à época abrigava uma população de 13.677 .475 habitantes, o que equivalia a aproximadamente $7 \%$ da população do país (IBGE, 2010). No processo diferenciado de acumulação do capital e de ocupação do território nacional ao longo do século XX, o Centro-Oeste foi pensado como um grande vazio demográfico, mas com grande potencial de crescimento econômico, sobretudo relacionado ao desenvolvimento das atividades agropecuárias (CAVALCANTI; BARREIRA, 2011, p.180).

Em função do legado histórico das principais atividades produtivas da região - mineração e pecuária - a estrutura da rede urbana regional nas primeiras décadas do século XX apresentava-se com alto grau de dispersão, centrado em poucos núcleos de expressão regional.

Suas características naturais e sociais somadas à centralidade no espaço geográfico nacional configuraram o Centro-Oeste como uma região de grande potencial de crescimento econômico, reclamando e possibilitando grandes intervenções do Estado brasileiro em seu território. Os primeiros discursos governamentais de legitimação da ocupação dessa região, no âmbito do ideário nacional-desenvolvimentista, foram promulgados na década 
de 1930. Nesse contexto, Getúlio Vargas lançou diferentes estratégias de ocupação territorial e povoamento dessa porção do território nacional através da Marcha para Oeste, com o objetivo de estimular a migração de camponeses e trabalhadores rurais para novos núcleos de colonização e ocupação da parte central do Brasil.

Como parte desse movimento, em 1937, foi construída a cidade de Goiânia, reforçando o processo de interiorização da economia brasileira e constituição de um centro socioeconômico no eixo Goiânia-Anápolis. Além disso, Leme e Guimarães (GUIMARÃES, 1997) destacam que, ao longo dos anos 1930-1945, existiu uma política deliberada do governo federal de ampliação e ocupação das fronteiras denominada de Marcha para o Oeste. Nesse sentido, destacam-se duas experiências de colonização: a Colônia Agrícola Nacional de Goiás e a Colônia Pecuária Nacional de Dourados (MS).

Complementarmente, Cavalcanti (CAVALCANTI, 2009) ressalta que a ocupação produtiva do Centro-Oeste justificava-se também pela necessidade de povoamento da Amazônia, enquanto etapa futura, mediante abertura da fronteira agrícola em direção à região Norte, possibilitada pela fixação de excedentes populacionais originados principalmente do Nordeste, bem como meio de proteção do território nacional dos avanços da frente populacional originados de países como Paraguai e Bolívia. A observação sobre o processo de ocupação do Centro-Oeste como etapa ou percurso necessário à ocupação da Amazônia também foi elaborada por Silvada de Abreu ao fazer referência ao conceito de "espaço de transição", entendendo-o como geopolítico que estaria vinculado ao domínio e consolidação das fronteiras políticas (ABREU, 2014, p. 68)

Destarte os esforços governamentais ao longo do período citado, foi a partir do Programa de Metas que se verificou uma mudança entre o processo de ocupação do período anterior - caracterizado pelas frentes de subsistência e a produção pecuária rudimentar e a inserção do Centro-Oeste em um novo padrão de acumulação de capitais através da modernização do processo produtivo. A interiorização forçada do desenvolvimento via construção da nova Capital Federal possibilitou ao Centro-Oeste usufruir de condição única no processo de intenso crescimento econômico que marcou o fim da década de 1950.

Nesse período, grandes obras de infraestrutura permitiram a consolidação dessa porção do território nacional, redefinindo espacialmente o papel da fronteira agrícola como apoio ao mercado interno, bem como o fomento da acumulação de capitais e a diversificação produtiva por alguns núcleos urbanos regionais (LEME; GUIMARAES, 1999). Ademais, Steinberger chama atenção para o fato de que a importância conferida ao Centro-Oeste encontra seus motivos na sua posição geográfica de centralidade nacional, sobretudo da sua configuração como ponto de encontro, quando se constata a existência de um processo de construção da unidade regional, que é fruto da representação da diversidade brasileira no seu território, tanto em termos fisiográficos, como socioeconômicos, culturais e políticos. Essa relação unidade-diversidade resulta da associação entre as características intrínsecas ao espaço fisiográfico onde se assentou e as características adquiridas a partir da continuada intervenção estatal (STEINBERGER, 2000, p.35).

Nesse sentido, o Centro-Oeste foi considerado pelo estrategista Golbery na década de 1950/1960 como elemento-chave de integração nacional. Segundo Steinberger (2000), Golbery considerou, juntamente com o Sul e o Nordeste, uma das três penínsulas que deve articular-se, por meio de istmos de circulação, ao que foi denominado 
Tabela 1: Incremento Populacional. Fonte: IBGE, Diretoria de Pesquisas, Departamento de População e Indicadores Sociais, Censo Demográfico. 'plataforma ou núcleo central', formado pelo triângulo de potência de Rio-São PauloBelo Horizonte (STEINBERGER, 2000).

Assim, a atividade agroindustrial emergiu como o dispositivo mais apropriado no que concerne à integração regional, pelos efeitos decorrentes de suas demandas relacionadas à infraestrutura de modo geral. Essa proposta de especificação produtiva do Centro-Oeste na divisão inter-regional nacional foi desenvolvida ao longo do período 1960-1980, em que se verificou a modernização agropecuária, responsável pelo salto produtivo dessa região.

Com base nessas peculiaridades, foram definidas três grandes estratégias para a região Centro-Oeste, direcionado as seguintes funções no conjunto do sistema nacional:

- Produção de alimentos e matérias-primas integradas às atividades industriais, voltadas para exportação;

- Absorção e reorientação das correntes espaciais de mão de obra;

- Servir de área alternativa para desconcentração industrial do país.

Esse conjunto de intervenções estatais no território central do país desencadeou uma série de efeitos em sua estrutura demográfica, resultando em um incremento populacional bastante significativo, conforme apresentado na Tabela 1.

Como se pode perceber, a população urbana da região Centro-Oeste quintuplicou no período de 1950/1970, ao passar de 437.100 habitantes em 1950 para 2.522.700 em 1970. Em 1950, não existia no Centro-Oeste nenhuma aglomeração com mais de 100.000 mil habitantes, registrando-se uma, em 1960, e três, em 1970. Os principais centros urbanos da Região Centro-Oeste, dentre as 38 aglomerações existentes, apresentaram no período 1960/1970 as seguintes taxas de crescimento:

- Brasília - 14,4\%

- Goiânia-9,3\%

- Anápolis - 5,1\%

- Campo Grande-6,9\%

- Cuiabá-6,3\%

\begin{tabular}{llllll}
\hline & $\mathbf{1 9 4 0 / 1 9 5 0}$ & $\mathbf{1 9 5 0 / 1 9 6 0}$ & $\mathbf{1 9 6 0 / 1 9 7 0}$ & $\mathbf{1 9 7 0 / 1 9 8 0}$ \\
\hline Brasil & 26,0 & 34,9 & 32,9 & 27,8 \\
Centro-Oeste & 38,0 & 69,4 & 72,4 & 48,7 \\
Mato Grosso & 20,8 & 70,4 & 79,5 & $-28,7$ \\
Goiás & 47,0 & 57,5 & 53,6 & 31,3 \\
Distrito Federal & 0,0 & 0,0 & 283,5 & 119,0 \\
\hline
\end{tabular}


Esses dados mostram que o conjunto de intervenções realizadas pelo Governo Federal a partir da década de 1950 acelerou as modificações intrarregionais. Aspectos relacionados ao adensamento demográfico, à intensificação dos desdobramentos de municípios e à relevante produção agropecuária possibilitaram a consolidação da porção central do território brasileiro em que a SUDECO exerceu papel fundamental.

\section{A Superintendência de Desenvolvimento do Centro-Oeste - SUDECO}

O cenário econômico, social e político consolidado a partir de 1964 reclamou, logo de início, pela instituição de órgãos de planejamento capazes de fazer frente ao projeto ditatorial de intensa produção industrial e reconfiguração do território nacional. A fim de atender aos interesses em jogo e consolidar a ocupação de parte central do Brasil, foi criada na gestão Costa e Silva, a SUDECO pela Lei $n^{\circ} 5.365$, de $1^{\circ}$ de dezembro de 1967, como entidade autárquica vinculada ao Ministério do Interior, tendo como seu primeiro superintendente o engenheiro Sebastião Dante de Camargo Júnior.

A sua criação não foi, contudo, um ato isolado, mas parte de um projeto institucional para formulação de uma política de desenvolvimento regional centralizada no Ministério do Interior e que ao mesmo tempo mantinha uma estrutura de planejamento coordenada pela Secretaria Geral do Ministério do Planejamento e Coordenação Geral. No fundo, o processo mais complexo e que envolveu já nos anos 1960, especialmente a partir de 1967, os Ministérios do Planejamento e do Interior numa disputa política e intelectual em pela hegemonia sobre condução da política urbana e regional no Brasil (FARIA, 2019).

A SUDECO teve de início a atribuição principal de atuar nos estados de Goiás e Mato Grosso, e sua criação teria tido uma relação de continuidade com ações da Fundação Brasil Central, criada em 1943, caracterizadas pela "urbanização e a modernização econômica e sociocultural e favorecendo a integração da área" (TREVISAN, RAMOS, 2020, p. 41). Em 1968, o estado de Rondônia foi constituído enquanto território nacional e passou a ser incorporado à área de abrangência da SUDECO. O Distrito Federal só veio a ser inserido em 1975, a partir de decisão do conselho deliberativo, aprovada pela Presidência da República.

Como missão central estava a elaboração e coordenação de Planos Diretores de Desenvolvimento Regional, os quais deveriam ser desenvolvidos a partir do atendimento de condições pré-definidas, quais sejam:

1) Realização de programas e pesquisas e levantamento do potencial econômico da região, com base para a ação planejada a curto e a longo prazo;

2) Definição dos espaços econômicos suscetíveis de desenvolvimento planejado com a fixação de polos de crescimento capazes de induzir o desenvolvimento de áreas vizinhas;

3) Concentração de recursos em áreas selecionadas em função do seu potencial e da sua população.

4) Adoção de política migratória para a região, com aproveitamento de excedentes populacionais internos e contingentes selecionados externos;

5) Coordenação e concentração da ação governamental nas tarefas de pesquisa, planejamento, implantação e expansão da infraestrutura econômica e social, reservando 
4 A expressão Aménagement du territoire exprime uma regionalização dos objetivos nacionais de desenvolvimento, mediante a análise de sistema prospectiva e localizada com a finalidade de melhoria do meio onde se desenvolve as atividades humanas.

Figura 3: Capa da Revista Interior. Fonte: Brasil, 1978a. à iniciativa privada as atividades agropecuárias, industriais, mercantis e de serviços básicos rentáveis.

Essas orientações estavam diretamente associadas à política de desenvolvimento do Governo Federal que naquele momento tinha como plano nacional o Plano Estratégico de Desenvolvimento (PED), cujos objetivos contemplavam a criação de um processo autossustentável de desenvolvimento em cada região e a inserção desse processo dentro de uma linha de integração nacional, com vistas à relativa diferenciação econômica de cada região e à formação de um mercado nacional integrado (BRASIL, 1967). Com base nessas diretrizes, e visando, sobretudo, a atenuação das disparidades regionais e sociais do País, o Superintendente Camargo Júnior proferiu o seguinte discurso:

o objetivo básico do desenvolvimento econômico é conseguir o bem comum e a distribuição equitativa dos frutos da produção. E isso exige que os investimentos públicos não sejam feitos apenas nas áreas mais desenvolvidas e produtivas, mas também, naquelas que representam potencialidade econômica, para que, com seu desenvolvimento, se elimine a disparidade entre as diversas regiões do País. (BRASIL, 1968, p. 32)

Dessa forma, cabia à SUDECO, enquanto instância de planejamento regional, os estudos das áreas potenciais para elaboração de planos de ações direcionados a induzir o desenvolvimento de áreas próximas a fim de direcionar de forma mais eficaz os parcos recursos disponíveis para a região. Procurava-se através da apropriação de teorias, como é o caso da teoria dos polos de desenvolvimento sob influência francesa do Aménagement du territoire ${ }^{4}$, estimular diferentes áreas potenciais distribuídas pelo território regional, com objetivo de "romper a pobreza", como destacado na capa da Revista Interior - Ministério do Interior.

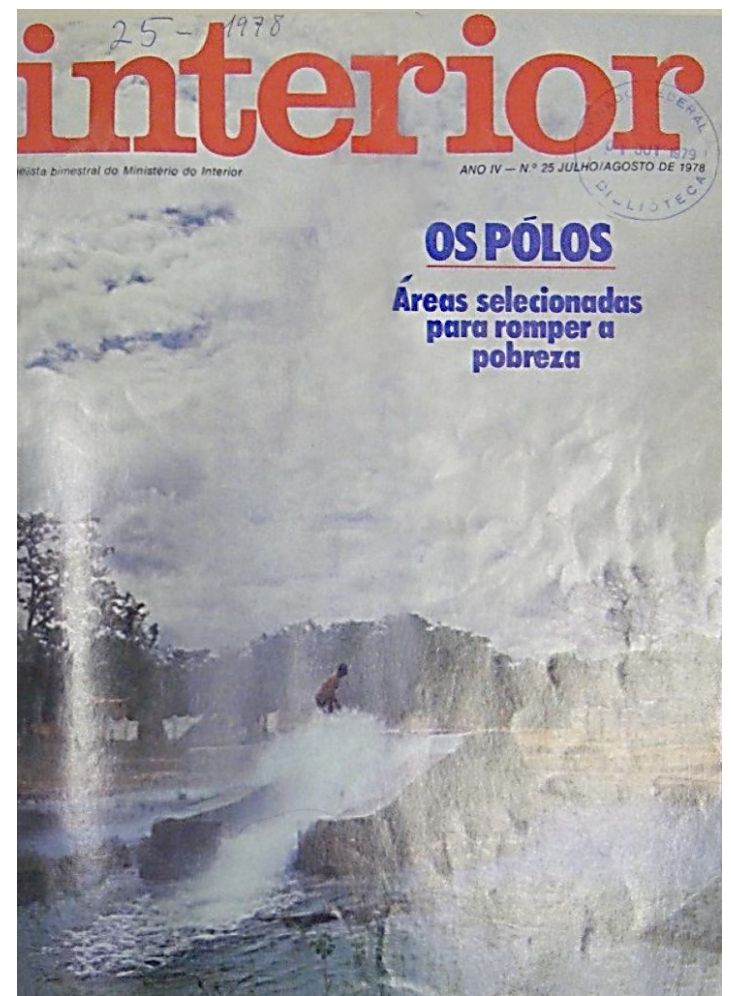


Com base nessa teoria buscava-se abordar o fenômeno das desigualdades regionais através de um diagnóstico global, a partir do qual eram expostos os condicionantes para estruturação de políticas de correção na escala nacional, dos desequilíbrios regionais, vislumbrando o papel do Estado enquanto gestor dessas ações. Esse posicionamento foi considerado por Serra (SERRA, ]1981) ao afirmar que essas políticas partem da premissa da possibilidade e da conveniência da atuação estatal. Citando Gunn (GUNN, 1985), o autor destaca o papel do "Estado instrumental que se transformou no sujeito da história com a organização social do território posta como seu predicado" (GUNN, 1985, apud Serra, 1981, p.23).

A instrumentalização espacial do Centro-Oeste pela atuação da SUDECO foi bastante notória. Fazia parte do discurso oficial medidas explícitas de desenvolvimento com base no deslocamento de contingentes populacionais como forma de atenuar as pressões nas metrópoles do Centro-Sul. A esse respeito o Superintendente Camargo Júnior declarava que deverão ser deslocados para o Centro-Oeste os excedentes populacionais nordestinos [...] numa atividade programada dirigida, capaz de trazer esses contingentes humanos, integrando no desenvolvimento nacional, fixando-os, através da propriedade da terra (BRASIL,.1968).

Ocorre que as ações da SUDECO foram, em grande medida, balizadas pelo desenvolvimento da grande propriedade latifundiária, que juntamente com o intenso emprego de capital e baixa utilização de mão-de-obra, desencadearam uma intensa liberação da população rural. Essa ausência de um exame mais apurado sobre a questão da estrutura latifundiária do Centro-Oeste naquele momento foi considerada por Cano. Segundo o autor a ocupação dos vazios do território brasileiro constitui escamoteação para uma das mais graves questões nacionais, que é a da reforma agrária (...) tal vazio, não está ocupado por homens trabalhando a terra, mais em sua maior parte pelo capital especulativo (CANO, 2007, p. 29).

Esse cenário veio a ser intensificado pelo II PND, ao apresentar uma "Estratégia nacional e política de população", pensada na colonização do Centro-Oeste e da Amazônia.

Em verdade, uma política demográfica insere-se em toda a textura da vida nacional, influenciando o planejamento e os processos de desenvolvimento sócio-econômico, com implicações quanto à segurança (...) É relevante, desse ângulo, o fato de que a ocupação de novas áreas - no Planalto Central, no Centro-Oeste, na Amazónia - pode representar significativa contribuição do Brasil à redução da escassez mundial de alimentos, minerais e outras matérias-primas, do final da década ao final do século. Para realizar-se sem uso excessivo do fator capital, tal expansão de fronteira económica implica em uso amplo de mão-de-obra. (BRASIL, 1975, p.57)

O êxodo rural provocado por essas medidas coincidiu com os primeiros anos que sucederam a inauguração de Brasília, contribuindo de forma significativa para a sua rápida urbanização. Ao longo do período ditatorial em que a SUDECO exerceu suas atividades, podem-se vislumbrar três fases distintas:

- Na primeira, os esforços iniciais do órgão recém-criado, ainda sem a estruturação condizente com sua grande tarefa, se orientaram para os aspectos puramente setoriais e dando ênfase à infraestrutura econômica, principalmente na parte de construção de rodovias. 
- A segunda fase se caracteriza pelo surgimento, em 1972, do primeiro Plano de Desenvolvimento Econômico e Social do Centro-Oeste - PLADESCO -, baseado na concepção espacial do desenvolvimento regional. Foram estabelecidas 13 áreasprograma vinculadas às grandes estratégias nacionais: i) integração nacional; ii) produção para exportação; iii) orientação de fluxos migratórios. Os programas especiais criados - Poloamazônia, Polocentro, Geoeconômica de Brasília e Grande Dourados, incorporam as áreas prioritárias indicadas no PLADESCO.

- A terceira fase se caracteriza pelo aprimoramento do planejamento integrado, através da operacionalização e acompanhamento dos Programas Especiais (INTERIOR, 1977).

Nesse sentido, o período de maior interesse ao presente estudo está localizado na segunda fase da atuação da SUDECO, quando se observou o enriquecimento dos debates a respeito das ações estatais voltadas para a criação de sistemas urbanos interdependentes entre si no âmbito do desenvolvimento regional, de certa forma, reafirmado no início dos anos 1970 pelo I PND. Com objetivo de ampliar o mercado nacional, criou programas que diretamente ou indiretamente atingiram o CentroOeste, a exemplo do Programa de Desenvolvimento do Centro-Oeste - PRODOESTE e Programa de Integração Nacional - PIN e mais especificamente a criação da Região Geoeconômica de Brasília (FREITAG, 2012), cujo objetivo principal passava pela compreensão de Brasília como polo irradiador de desenvolvimento do Planalto Central e pela sua inserção ao processo de desenvolvimento das demais regiões do Brasil, como destacado abaixo:

Ao lado das políticas relativas ao Nordeste e Norte, e das medidas em relação ao Centro-Oeste, a Política de Integração Nacional criará a Região Geo-Econômica de Brasília, integrando-a no processo de crescimento do Planalto Central e permitindo a sua articulação com as demais macro-regiões do País. Isso se fará, inclusive, pela complementação das rodovias radiais de Brasília — de interligação com as regiões do Programa de Integração Nacional. (PIN) (BRASIL, 1971)

Essas estratégias configuravam-se sob o reconhecimento do espaço regional como uma sobreposição de áreas econômicas e que o encadeamento do processo de desenvolvimento deveria se apoiar em ações que fossem capazes de gerar economias externas e possibilitar o surgimento de economia de escala por meio da ocupação de espaços potenciais e da dinamização das produções econômicas existentes. Nesse sentido, a partir de 1975, foram criados no âmbito do II PND, os Programas Especiais como instrumentos para um efetivo desenvolvimento regional, alinhando-os às diretrizes do Governo Federal no sentido da integração nacional, produção de alimentos e contenção dos fluxos migratórios, entre os quais destacava-se o Programa Especial da Região Geoeconômica de Brasília - PERGEB (FREITAG, 2012).

Esses Programas fundamentavam suas ações em uma compreensão espacial de desenvolvimento, com a seleção de áreas-programas sistematizadas de acordo com as características locais naturais como bacias hidrográficas, vegetação e aspectos sociais e econômicos, como demonstrado pelo mapa do PERGEB (figura 4).

Essas ações ilustram que a inserção do Centro-Oeste brasileiro nas ações governamentais foi operacionalizada como mecanismo estratégico no contexto das prioridades nacionais. 


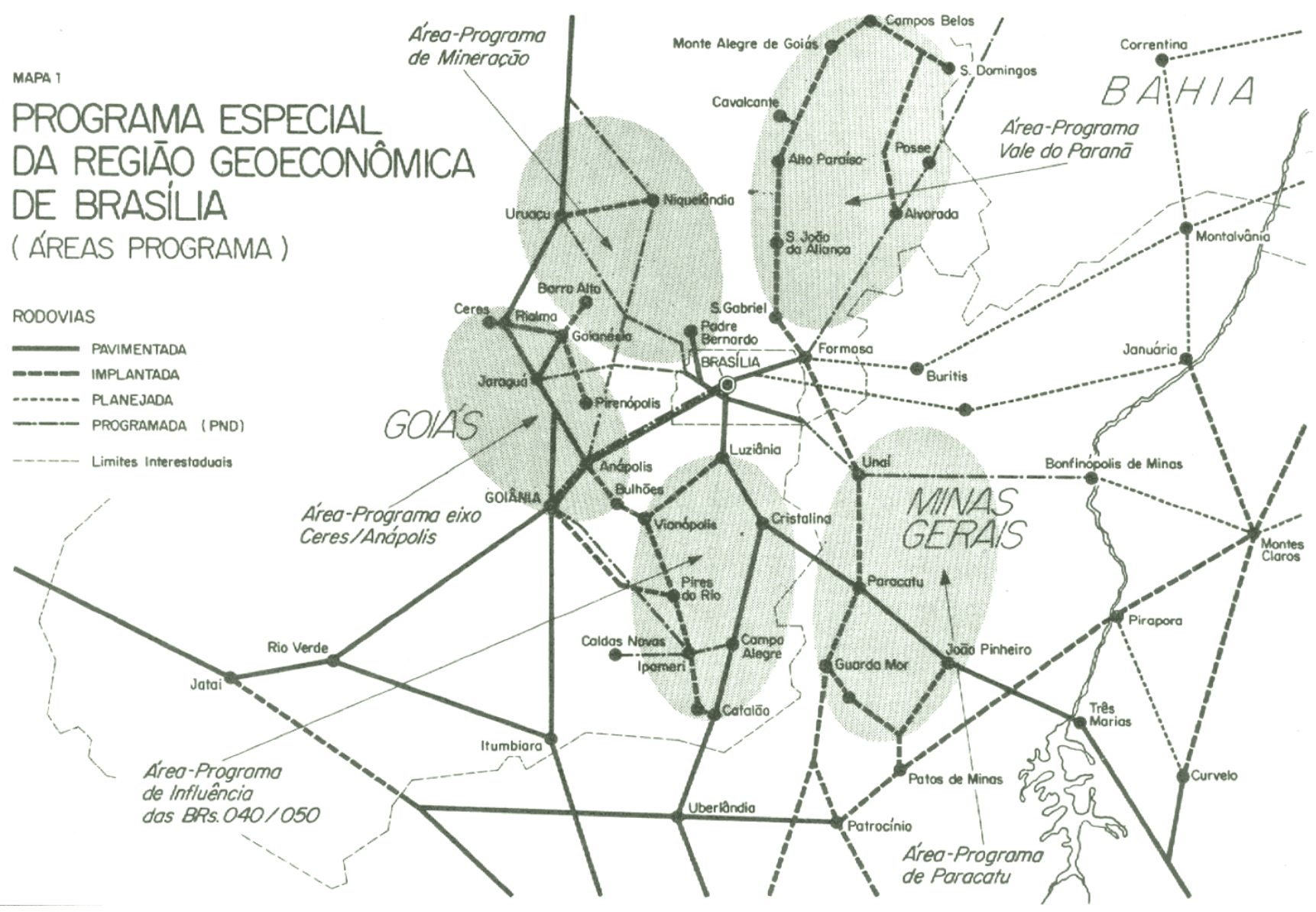

Figura 4: Programa Especial da Região Geoeconômica de Brasília. Fonte: Brasil, 1978, p. 52.
A esse respeito Abreu (ABREU, 2001), considera que a atuação da SUDECO pode ser compreendida a partir da

internalização do desenvolvimento como crescimento econômico e planejamento como uma rede racional de ações isentas de intenções político-ideológicas (ainda que houvesse quem declarasse e declare motivos ideológicos, como é o caso do General Golbery da Costa e Silva). Esse é o pensamento que perpassa todos os governos militares. O conceito de desenvolvimento elaborado está voltado para o problema da superação do subdesenvolvimento através da autodeterminação nacional em torno do parâmetro nação, na proposição de um capitalismo autônomo. (ABREU, 2001, p.79)

Dentro desse projeto traçado pelos governos militares, a Região Geoeconômica de Brasília foi considerada como elemento de grande importância no processo necessário de reordenamento territorial alinhado aos interesses nacionais. Pode-se caracterizar que a linha de ação regional da SUDECO, objetivando o desenvolvimento integrado, estruturava-se da seguinte forma (figura 5): 


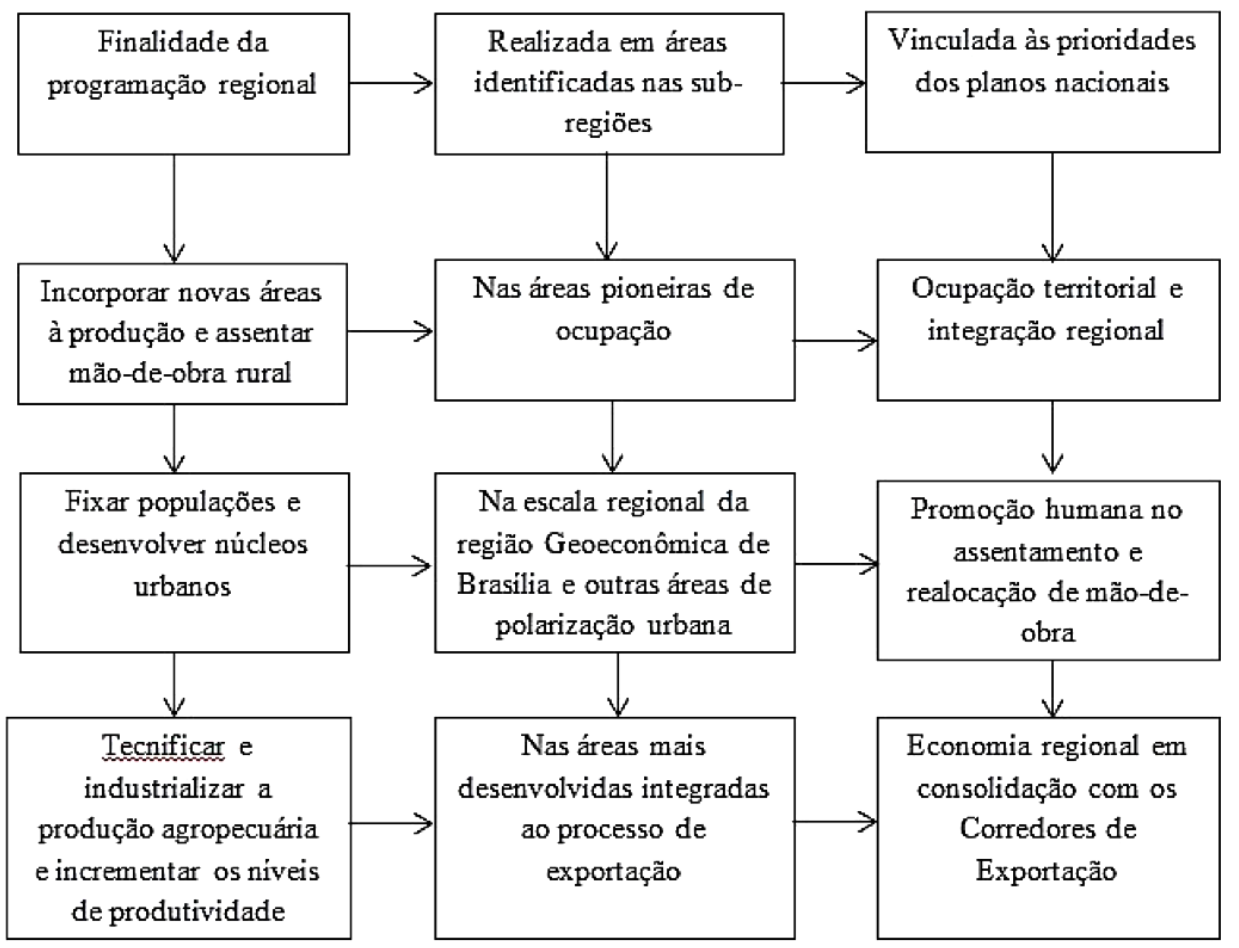

Figura 5: SUDECO - estruturação das ações de desenvolvimento integrado Revista Interior, Ministério do Interior, Ano III - No 21, novembro de 1977.
Note-se que a Região Geoeconômica de Brasília é referenciada no organograma acima através da conjugação de vários objetivos, o que nos leva a concluir que o Programa Especial voltado para a Região Geoeconômica de Brasília -o PERGEB - foi criado com propósitos amplos e significativos para o desenvolvimento nacional. Embora tenha sido elaborado sobre pressões de se atenuar os efeitos nefastos já conhecidos da metropolização e assim manter o caráter administrativo e cultural de Brasília, é lícito observar que seu papel não pode ser reduzido apenas a um instrumento de contenção migratória, mas como uma das mais interessantes ações governamentais elaboradas no contexto dos governos militares, por se tratar de um entroncamento entre objetivos locais, regionais e nacionais, atento às diretrizes tanto do planejamento nacional, como da política urbana e do planejamento regional pensados naquele período.

\section{Brasília e o Centro-Oeste: uma dicotomia}

A análise da construção de Brasília, pela perspectiva de sua inserção na estruturação de um espaço geográfico nacional, revela seu papel na geração de uma nova regionalização, sendo identificada por Versentini (VERSENTINI, 1986) como um marco no reordenamento territorial do País. Sua importância nesse processo foi reforçada pela construção de todo um aparato infraestrutural necessário para o desempenho de sua função como capital. Assim, muito mais importante do que o papel de sede administrativa a ser desempenhado pela cidade-capital, foram as obras de infraestrutura - implantação de hidrelétricas, novos aeroportos, indústria naval e abertura de novas rodovias no centro do território nacional - responsáveis por profundas mudanças na expansão da economia regional e na correlata consolidação da fronteira. 
Nesse contexto, Estevam (ESTEVAN, 1997) ressalta que o Estado de Goiás foi particularmente beneficiado com os projetos rodoviaristas, apresentando no início da década de 1960, salto quantitativo/qualitativo bastante expressivo na extensão de sua malha viária, de 520 km de rodovias federais em 1952, para 2.782 em 1960.

Dessa forma, ao tomarmos em consideração o conjunto desses esforços, torna-se clara as intenções resguardadas por trás da transferência da capital: a ocupação do centro do território nacional, visando à integração e unificação nacional, como uma 'ponte' no alcance às regiões ainda pouco exploradas por aquelas mais desenvolvidas. Posto assim, a construção da Capital Federal no Planalto Central pode ser considerada como um dos mais significativos projetos governamentais já implementados no País, não apenas pelo modelo urbanístico proposto, mas por se tratar de uma estratégia que propõe o alcance de objetivos nacionais ancorados no planejamento regional. Ou seja, mais que uma discussão de projeto e concepção urbanística, uma ação pensada como parte das ações governamentais para o país e o Centro-Oeste e que incluíam necessariamente a região Nordeste com a criação pela SUDENE pouco antes da inauguração de Brasília (LANER, 2018; LANER, FARIA, 2019; LANER, FARIA, PESCATORI, 2019)

A partir da observância dessa conjunção, Steinberger (1999) chama atenção para o seguinte aspecto: não parece ter sido uma mera coincidência que a criação da SUDENE, marco inicial do planejamento regional, e a implantação de Brasília tenham (...) sido frutos de decisões concretizadas contemporaneamente (STEINBERGER, 1999, p.38). Entretanto, embora as evidências deixem claro o grau de vinculação da construção da capital nacional com a questão regional no Brasil, em um período histórico de consideráveis avanços nas discussões que problematizavam a região como unidade administrativa, o planejamento regional não foi substancialmente considerado quando da elaboração específica do projeto urbanístico de implantação de Brasília, como também observado por Maria Fernanda Derntl (DERNTL, 2019, p.30).

Essa observação apoia-se no fato de que à época de sua construção, na década de 1950, a questão regional era, em grande medida, fundamentada no entendimento de que o seu desenvolvimento se daria a partir de "polos de crescimento", como teorizado por François Perroux. A ideia, já amplamente difundida, era de que as regiões seriam desenvolvidas a partir de núcleos urbanos devidamente equipados, com capacidade de irradiar inovações, tecnologia e provocar produção/consumo com efeito de espraiamento. Ou seja, pressupunha-se que a concentração dos investimentos em áreas específicas do território desencadearia efeitos potencializadores relevantes, espalhando-os por toda a rede urbana. Essa expectativa foi traduzida por Serra (1991) da seguinte forma:

No Brasil, quase toda a política de desenvolvimento regional tem implicado certo tipo de ação sobre polos de desenvolvimento. Com frequência, a ideia traz consigo noções sobre a difusão de hábitos de consumo ou aspectos culturais, como se o polo fosse uma "mancha de óleo", de onde fosse possivel irradiar modernização. (SERRA, 1991, p.23)

Assim, por efeito da influência dessa teoria nas políticas de desenvolvimento regional brasileiro, Lúcio Costa anunciou no relatório desenvolvido para o plano urbanístico de Brasília, que [...] esta (a cidade de Brasília) não será, no caso, uma decorrência do planejamento regional, mas a causa dele: a sua fundação é que dará ensejo ao ulterior 
5 A respeito de estruturas urbanas implantadas artificialmente, Milton Santos (1980) observa que: "as cidades aparecem muitas vezes como um corpo estranho, inserido em um meio com o qual estabelecem relações descontínuas no espaço e no tempo, não fazendo parte integrante do território em que se encontram, que não as teria gerado e com o qual elas não evoluíram a partir de constantes interações. Isso significa afirmar que o surgimento e desenvolvimento de nossas cidades não traz consigo uma correlação perfeita com o desenvolvimento de seu hinterland" (SANTOS, 1980, p. 97).

6 Obviamente que com a construção da capital federal essa divisão se ampliou e se consolidou, mas não ao ponto de se atribuir à sua construção os efeitos maiores da expansão do mercado produtor agrário. desenvolvimento planejado da região. Trata-se de um ato deliberado de posse, de um gesto de sentido ainda desbravador, nos moldes da tradição colonial (COSTA, 1965; 343).

Contudo, essas teorias foram apropriadas sem um exame atento aos elementos locais e regionais. Brasília foi implantada em uma área de estrutura produtiva pouco eficiente e diversificada, onde as atividades econômicas vinculavam-se à pecuária extensiva e à agricultura de subsistência. Esse cenário contrastava com um equipamento social urbano privilegiado, notadamente no Plano Piloto, onde a alta renda de parte significativa da população provinha da capacidade de drenar uma porção relevante da receita nacional em função de sua condição de centro do poder público nacional. Em outras palavras, construíra-se um oásis num deserto de pobreza, um 'emirado' sem fronteiras no seio de uma região ainda não alcançada pelos reflexos do desenvolvimento econômico nacional (BRASIL, 1981b, p.2). Corroborando com essa observação, o economista Paulo Timm, ao se referir à implantação da nova capital no Planalto Central acrescenta:

A área escolhida para receber a nova capital proporcionou-lhe acolhimento eufórico, mas absolutamente despreparado. Para ela, Brasília não passou de um grande susto que os anos posteriores dourariam como promessa, para afinal converter-se, talvez, em pesadelo. Por quê? Porque não havia uma região previamente organizada à qual se integraria Brasilia como fonte de virtudes. Até mesmo o plano aprovado percebia essa situação e não escondia a pretensão de que, a região, afinal fosse uma consequência da cidade que, erigida e desdobrada sobre sua escala regional, estabeleceria os nexos que até então a história havia negado. (TIMM, 1990, p.74)

Tratava-se, portanto, de uma dicotomia entre Brasília e seu entorno, uma cidade de concepção urbanística moderna e com uma população de alta renda, em meio a uma região desprovida de condições mínimas de infraestrutura ${ }^{5}$, que notoriamente apresentava incapacidade de responder a esses estímulos, seja pela falta de suporte financeiro, econômico e tecnológico, seja pelo processo rudimentar de produção e industrialização incipiente de produtos primários. Nesse sentido, Aldo Paviani (PAVIANI, 2003) observa que o desenvolvimento regional não ocorreu através de um efeito exógeno e contínuo no entorno dos pólos de crescimento como idealizado na teoria da polarização, mas do efeito de aglomeração (endógeno) em centros já existentes, como em Brasília e Goiânia.

É evidente que com o crescimento progressivo desses dois centros urbanos houve um efeito impulsor na produção agrária, em função da demanda por alimentos pela população que crescia em razão das oportunidades de trabalho no eixo Brasília, Anápolis e Goiânia. Apesar disso, Paviani (2003) afirma que não há como sustentar que o desenvolvimento da agricultura ou dessas cidades se deu por 'efeitos de esparramamento' (trickle down effects) ou 'de barragem' (backwash effects), como teorizavam os desenvolvimentistas (PAVIANI, 2003, p.68).

No nosso entender, essa constatação pode ser atribuída mais ao fato de que o desenvolvimento do Centro-Oeste a partir da agricultura era antes resultado de uma deliberação histórica do capitalismo brasileiro para o qual foram atribuídos papéis de fronteira agrícola na divisão nacional e regional do trabalho, do que propriamente o resultado do crescimento urbano ${ }^{6}$. Tratava-se de um contexto em que o planejamento 
já vislumbrava práticas de cunho inter-regionais, em que cada região desempenharia suas respectivas funções a partir de suas particularidades. Nesse sentido, em resposta aos estímulos de mercado (nacional e regional), houve uma ocupação de territórios pelos grandes produtores agrícolas, definindo a estrutura fundiária local através da grande propriedade.

Associado a esse fenômeno, os objetivos apresentados pelo Governo Federal através da SUDECO, entre os quais de contenção dos excedentes populacionais provenientes de áreas estagnadas, contribuiu para o agravamento do crescimento urbano das principais cidades dessa região. Isso porque, embora tenham sido apresentadas medidas visando o fortalecimento dos municípios circunscritos por essa região, o que se observou foi uma incompatibilidade entre o que estava sendo proposto pelos planos nacionais e a estrutura produtiva local. A mecanização intensiva das atividades rurais somada à precária atenção governamental aos núcleos urbanos de baixa expressividade econômica resultou na liberação do homem do campo para as cidades de maior potencial de crescimento econômico.

Assim é que Goiânia e Brasília cresceram para além das expectativas, com um agravante, qual seja, esse crescimento se deu de forma endógena, implicando em efeitos em sua estrutura interna semelhante às demais metrópoles brasileiras, ou seja, crescimento exacerbado das respectivas malhas urbanas com o surgimento de construções irregulares e ocupações ilegais de terras públicas, sobretudo, no caso da Capital Federal, mas, ao mesmo tempo, a partir de uma estruturação urbano-regional que tem nas cidades satélites um aspecto importante (DERNTL, 2019) A interpretação de que Brasília não logrou cumprir, a rigor, a função de polo regional é compartilhada por Leme e Guimarães (LEME e GUIMARÃES, 1997). Entretanto, os autores ressaltam que não significa que sua importância tenha se reduzido a uma economia de enclave como sugerido por alguns estudos e ressaltam que o fato de não ter cumprido a função de pólo não minimiza a grande função regional que a localização de Brasília provocou no Centro-Oeste. Os impactos da construção de Brasília foram muito além da existência material da cidade e seus efeitos foram significativos para a economia regional (LEME; GUIMARÃES, 1997, p.75).

Ainda sobre o caso de Brasília, as consequências desses efeitos foram sentidas de forma bastante peculiar devido à presença de três fatores: a) o Estado detentor de grande parte das terras; b) o interesse em resguardar o caráter cultural e administrativo de Brasília, mantendo-a livre de interferências diversas em sua base socioeconômica; c) a necessidade de fortalecer economicamente os municípios pertencentes à sua hinterlândia, afinal a atribuição dada à Capital Federal de agente de integração nacional não era abandonada pelas instâncias de planejamento governamental do período militar, que visavam, fundamentalmente, a ocupação do território brasileiro. Tratava-se de interesses e objetivos explicitamente distintos, formulados a partir das ideias matrizes que deram causa a construção de Brasília como Capital Federal e Polo de Desenvolvimento, abordados paralelamente tanto em sua idealização quanto na sua implantação.

\section{Considerações Finais}

Se por um lado eram direcionados esforços para a dinamização da região através da implantação de infraestrutura e do planejamento demográfico visando à ocupação do 
território central, tendo Brasília como núcleo econômico, político, cultural e financeiro desse processo de desenvolvimento, por outro, o pensamento de preservação do projeto urbanístico do Plano Piloto ocupava lugar de destaque nas discussões acerca do processo de planejamento da Capital Federal. A ideia Brasília-Capital induz à limitação do seu crescimento, à contenção de sua economia produtiva, à monumentalidade das construções, ao domínio estatal de suas áreas rurais. Distintamente, a ideia de Brasília como polo de desenvolvimento sugere a expansão, a industrialização, o crescimento demográfico, a economia e funcionalidade como prioridade nas intervenções, o que incluiria as chamadas cidades satélites e toda a macrorregião do seu entorno.

Entretanto, embora pudesse existir essa divergência entre objetivos e a ideia de BrasíliaCapital ter sido dominante em vários momentos, a necessidade de consolidação da sua escala regional se impôs, sem a qual não haveria justificativa para sua interiorização. A importância dessa concretização foi traduzida por Timm (1998) da seguinte forma: "Brasília está para o Centro-Oeste como a Sudene para o Nordeste ou a Suframa para a Amazônia" (TIMM, 1998, p.55). É lícito observar, contudo, que a visão regional começou a ser delineada em função do processo de metropolização da Capital Federal, pois estava em jogo, na verdade, a viabilidade de Brasília como capital políticoadministrativa (BRASIL, 1978, p.46). A preocupação era de que no final do século $\mathrm{XX}$, Brasília se assemelhasse às demais metrópoles brasileiras, com os problemas que Ihe são próprios - poluição, dificuldade de mobilidade, continuada degradação da qualidade de vida - o que impossibilitaria, segundo os discursos oficiais, o desempenho da função de Capital do País. Nesse sentido, o relacionamento de Brasília com o seu entorno passou a ser objeto de discussão pelas entidades governamentais já na década de 1960. A pergunta que se fazia era: como proceder em relação a Brasília? Uma cidade nova, com problemas tão graves quanto os de cidades centenárias, uma cidade monofuncional, que reclamava desenvolvimento.

Essa "angústia" foi retratada pelo engenheiro Orlandi em 1974 durante o I Seminário de Estudos dos Problemas Urbanos de Brasília: Como se não bastasse o surpreendente progresso brasileiro, que derruba e supera os planejadores, Brasília também, por vezes, nos apresenta sua face de enigma, sua figura de incógnita. Dado a suas características inovadoras, a cidade se agiganta ante seus técnicos, criando barreiras de difícil transposição, por nunca terem sido vistas, nunca sentidas, nunca vividas (ORLANDI, 1974, p.37).

Tratava-se, portanto, de um desafio que emergia aos planejadores brasileiros. Apesar dos conhecimentos até então acumulados no campo do urbanismo, Brasília, em função de suas inúmeras peculiaridades, não se enquadrava às experiências adquiridas. Devido aos interesses em preservar os objetivos distintos, como visto anteriormente, os problemas urbanos da Capital Federal foram abordados naquele momento via política de desenvolvimento regional, contribuindo para a ampliação das reflexões acerca do planejamento regional. Ou seja, as demandas de se pensar Brasília em um contexto regional, foram motivadas pela necessidade de conter os fluxos migratórios para a qual fluíam. Além disso, essa problemática coincidiu com o momento histórico de elaboração da política urbana nacional nas décadas de 1960 e 1970, que fortalecia a função das cidades enquanto elemento de reordenamento territorial nacional. E é inegável que Brasília e as demais cidades da Região CentroOeste, sejam elas as capitais ou cidades do interior dos Estados dessa região, 
tiveram papel relevante no processo de estruturação do território nacional, por isso a importância em compreender historicamente a ideias e ações que nortearam as atividades da SUDECO, a agência governamental responsável pelo planejamento regional dessa complexa hinterland.

\section{Referências bibliográficas}

ABREU, Silvana de. Planejamento governamental: A SUDECO no espaço Mato-Grossense. Contexto, propósitos e contradições. 2001. 323 p. Tese (Doutorado em Geografia). Faculdade de Filosofia, Letras e Ciências Humanas, Universidade de São Paulo, São Paulo, SP, 2001.

Planejamento governamental: a SUDECO no espaço Mato-grossense, contexto, propósitos e contradições / Silvana de Abreu. - Dourados, MS: UFGD, 2014.

ARAÚJO, T. B. A experiência do planejamento regional no Brasil. In: LAVINAS, L. et al.

BAGGIO, Ulysses da C. Diferenciação Espacial e Análise Regional sob a Condição Capitalista na Contemporaneidade. Cadernos Metrópole. n. 20, 2 sem,. p. 37-56, 2008.

BARAT, Josef. Logística, transporte e desenvolvimento econômico. Local: CLA, 2007. 4 volumes.

BRASIL. Ministério do Interior. A ação do Ministério do Interior e Desenvolvimento Nacional. Brasília: Gráfica Alvorada, 1978b.

Revista Interior, Ano III - N²1, novembro de 1977

Revista Interior. Ano IV - n² 25 Julho Agosto, 1978a

BRASIL. Ministério do Interior/SUDECO. Integração nacional: discursos e conferências. Brasília - DF, 1968.

BRASIL, Presidência da República. Plano Decenal. Brasília: Ministério do Planejamento e Coordenação Econômica. 1967.

Plano Trienal de Desenvolvimento Econômico e Social (1963-1965). Brasília: Ministério do Planejamento e Coordenação Econômica. 1962.

Programa de Ação Econômica para o Governo. Brasília: Ministério do Planejamento e Coordenação Econômica. 1964.

BRASIL. Senado Federal. Revista de Informação Legislativa. Brasília-DF. 1966.

CANO, Wilson. Desequilíbrios regionais e concentração industrial no Brasil: 1930-1970. Campinas/São Paulo: Edunicamp/Global, 2007.

CARLEIAL, Liana. A Questão Regional no Brasil Contemporâneo. In: LAVINAS, L. et al. (Org.). Reestruturação do espaço urbano e regional no Brasil. São Paulo: Anpur, p. 35-58. 1993

CAVALCANTI, Henrique B. Distrito Federal - O Governo e a Comunidade. In: Anais do / Seminário de Estudos dos Problemas Urbanos de Brasília. Senado Federal. Brasília. 1974.

CAVALCANTI, Marcelo A. A concepção e atuação dos Programas da Superintendência de Desenvolvimento do Centro-Oeste - SUDECO - no território goiânio (1975 - 1985). 2009. Dissertação (Mestrado em Geografia). Universidade Federal de Goiás, Goiânia, GO, 2009.

CAVALCANTI, Marcelo A.; BARREIRA, Celena Cunha M. A. Ações da SUDECO no desenvolvimento do Centro-Oeste no Estado de Goiás. In: Boletim Goiâno Geográfico. V 31, n. 2, p. 179-191, jul/dez, 2011.

CINTRA, Antônio C.; HADDAD, Paulo R. Dilemas do planejamento urbano e regional no Brasil. Rio de Janeiro: Zahar Editores, 1978.

CORREA, Roberto Lobato. O Espaço Urbano. 3 ed. São Paulo: Ática, 1995. 
COSTA, Jorge Gustavo. Planejamento Governamental: a experiência brasileira. Rio de Janeiro: FGV, 1971

COSTA, Lucio. Consideração em torno do Plano Piloto de Brasília. In: Anais do I Seminário de Estudos dos Problemas Urbanos de Brasília. Senado Federal. 1974.

Relatório sobre o Plano Piloto de Brasília. In: IBAM. Leituras de Planejamento e Urbanismo. Rio de Janeiro. IBAM. 1965

DERNTL, Maria Fernanda. O Plano Piloto e os planos regionais para Brasília entre fins da década de 1940 e início dos anos 60. In: Rev. Bras. Estud. Urbanos Reg. [online]. 2019, vol.21, n.1, pp.26-44. Epub Jan 01, 2019.

ESTEVAM, Luís. O tempo da transformação: estrutura e dinâmica da formação econômica de Goiás. Tese. (Doutorado em Economia). Unicamp. Campinas. SP. 1997.

FARIA, Rodrigo de. O planejamento urbano no Brasil entre a democracia e o autoritarismo: uma interpretação em quatro dimensões. In: LEME, Maria C. da Silva. Urbanismo e Política no Brasil dos anos 1960. São Paulo: Anablumme, 2019

FREITAG, Patricia B. A institucionalização do planejamento regional de Brasília: o FUNDEFE e o PERGEB sob a lógica da metropolização

GUIMARÃES NETO, Leonardo. Trajetória Econômica de uma Região Periférica. Estudos Avançados. 11 (29), 1997.

HARVEY, David. A Produção Capitalista do Espaço. São Paulo. Ed. AnnaBlume. 2006.

IANNI, Octávio. Estado e planejamento econômico no Brasil. $4^{a}$ Edição. Rio de Janeiro. Ed. Civilização Brasileira, 1986.

IBGE. Censo Demográfico 2010. Instituto Brasileiro de Geografia Estatística, 2011.

LAFER, Celso. O Planejamento no Brasil: Observações sobre o Plano de Metas (1956-1961). In: Mindlin, Betty (Org.). Planejamento no Brasil. 5. ed. São Paulo: Perspectiva, 2001. p. 29-50.

LANER, Izadora C. Planejamento regional e desenvolvimento no Brasil: 1955-1961. Dissertação de Mestrado apresentada ao PPGFAU-UnB, 2018.

LANER, Izadora C.; FARIA, Rodrigo de; DA SILVA, Carolina P. Cândido. O ESTADO E O PLANEJAMENTO REGIONAL NO BRASIL DE 1955 A 1961: Perspectivas de análise. In: Anais do XVIII ENANPUR, 2019.

LANER, Izadora V; FARIA, Rodrigo de. Operação Nordeste: A criação da Sudene como política regional de desenvolvimento e integração nacional. In: Revista Política e Planejamento Regional. vol. 6, n² 2, maio a agosto de 2019, p. 184 - 203. Disponível em: <http://www. revistappr.com.br/artigos/publicados/Operacao-Nordeste-A-criacao-da-Sudene-como-politica-regional-de-desenvolvimento-e-integracao-nacional.pdf>.

LEME, Heladio; GUIMARÃES, Eduardo. A Região Metropolitana de Brasília no Contexto Regional. Campinas: Unicamp. (Textos Nepo.)

Caracterização histórica e configuração espacial da estrutura produtiva do Centro-Oeste. Campinas: Unicamp. (Textos Nepo n. 33). 1997.

LOPES, Carlos Thomaz G. Planejamento, estado e crescimento. São Paulo: Pioneira, 1990.

MONTE-MÓR, R. L. As teorias urbanas e o planejamento urbano no Brasil. In: DINIZ \& CROCCO (Ed.). Economia Regional e Urbana: contribuições teóricas recentes Belo Horizonte: Editora UFMG, 2006. p. 61-85.

MONTE-MÓR, Roberto. Do Urbanismo à Política Urbana: notas sobre a experiência brasileira. In: COSTA, Geraldo; MENDONÇA, Jupira. (Org.). Planejamento Urbano no Brasil: trajetória, avanços e perspectivas. Belo Horizonte: C/Arte, 2008. p. 31-65. 
OLIVEIRA, Francisco de. Elegia para uma Re(li)gião: SUDENE, Nordeste. Planejamento e Conflito de Classes. 3. ed. Rio de Janeiro: Paz e Terra, 1981.

OLIVEIRA, Francisco. O Estado e o Urbano no Brasil. Espaço e Debates, n. 6. São Paulo, p. $36,1982$.

ORLANDI, Geraldo. Brasília: Confronto entre o Planejamento Urbano original e a Realidade de Hoje. In: Anais do I Seminário de Estudos dos Problemas Urbanos de Brasília. Senado Federal. Brasília. 1974.

PAVIANI, Aldo. Brasília no Contexto Local e Regional: Urbanização e Crise. Revista Território. Rio de Janeiro. ano VII. $n^{\circ} 11,12$ e 13. Set./Out. 2003. p. 63-76.

SANTANA, Márcia. A Experiência de Planejamento Regional no Brasil: o caso da Amazônia (1985- 2003). 2009. 115 f. Tese (Doutorado em Area Planejamento Urbano e Regional) - IPPUR, Rio de Janeiro, 2009.

SCHMIDT, Benissio Viero. O Estado e a política urbana no Brasil. Porto Alegre: Editora da UFRGS, 1983.

SERRA, Geraldo. Urbanização e Centralismo Autoritário. São Paulo: Nobel/ Editora da Universidade de São Paulo, 1991.

SINGER, Paul I. Desenvolvimento e crise, 2.ed.. Rio de Janeiro, Paz e Terra, 1977. Economia Política da Urbanização. São Paulo: Brasiliense, 1987.

SOUZA, Maria Adélia A. O II PND e a Política Urbana Brasileira: Uma Contradição Evidente. In: DEAK C.; SCHIFFER, S. (Org.). O processo de urbanização no Brasil. São Paulo: Edusp/ Fupam, 1999.

STEINBERGER, Marília. Formação do Aglomerado Urbano de Brasília no Contexto Nacional e Regional. In: PAVIANNI, Aldo. Brasília - Gestão Urbana: conflitos e cidadania. Brasília: Ed. UnB, 1999.

STEINBERGER, Marília; BRUNA, Gilda C. Cidades médias: elos do urbano-regional e público-privado. In. ANDRADE, Thompson. A. e SERRA, Rodrigo V. (Org.). Cidades Médias Brasileiras. Rio de Janeiro: IPEA, 2001. p. 35-77.

TIMM, Paulo. Brasilianas. Brasília: Paralelo 15, 1998.

TOLOSA, Hamilton C. Política Urbana e Redistribuição de Renda. In: TOLEDO, A. H.; CAVALCANTI, M. (Org.). Planejamento Urbano em Debate. São Paulo: Cortez \& Moraes, 1977.

TORRES, Andréa. Imprensa: Política e Cidadania. Porto Alegre: EDIPUCRS, 1999.

TREVISAN, Ricardo; RAMOS, Edna Maria M. da Luz. SUDECO e Liquelândia (MT): o planejar uma cidade nova. In: Paranoá - Cadernos de Arquitetura e Urbanismo. N. 25, 2020, p. 38-55.

VAINER, C.; SMOLKA, M. Em tempos de liberalismo: tendências e desafios do planejamento urbano no Brasil. In: PIQUET, R.; RIBEIRO, A. (Org.). Brasil, território da desigualdade: descaminhos da modernização. Rio de Janeiro: J. Zahar, 1991.

VAINER, Carlos. Planejamento Territorial e Projeto Nacional: Os Desafios da Fragmentação. Revista Brasileira de Estudos Urbanos e Regionais, v. 9, n. 1 maio, 2007. 